\title{
Awareness of Health Implications of Agrochemical Use: Effects on Maize Production in Ejura-Sekyedumase Municipality, Ghana
}

\author{
Franklin N. Mabe, Kwadwo Talabi, and Gideon Danso-Abbeam \\ Department of Agricultural and Resource Economics, Faculty of Agribusiness and Communication Sciences, \\ University for Development Studies, Tamale, Ghana \\ Correspondence should be addressed to Gideon Danso-Abbeam; dansoabbeam@uds.edu.gh
}

Received 19 October 2016; Revised 28 December 2016; Accepted 4 January 2017; Published 20 February 2017

Academic Editor: Christos Tsadilas

Copyright (C) 2017 Franklin N. Mabe et al. This is an open access article distributed under the Creative Commons Attribution License, which permits unrestricted use, distribution, and reproduction in any medium, provided the original work is properly cited.

\begin{abstract}
This study assessed factors that affect awareness of health implications of agrochemical use and its effects on maize production in Ejura-Sekyedumase Municipality of Ashanti Region, Ghana. One hundred and fifty-four (154) maize farmers were randomly sampled from the municipality. The study used awareness indicators to estimate an index representing farmers' awareness levels of health implications of agrochemical use. An ordered logit compliment with multivariate linear regression model was used to identify the drivers of farmers' awareness level of health implications of agrochemical use. Also, a multivariate linear regression model was used to analyze the effects of health implications of agrochemical use on maize output. On average, the respondents have the moderate awareness level of health implications of agrochemical use (0.578). The awareness level was significantly explained by education, the number of children in school, ownership of TV/radio, experience in agrochemicals use, and farm size. The multivariate linear regression results showed that awareness levels of health implications of agrochemical use increase maize output. It is therefore recommended that interventions aimed at increasing farmers' awareness levels of health implications of agrochemicals use should focus on educating farmers through interactive radio discussion and training sessions on the field and incorporate safety use of agrochemical in our educational curriculum.
\end{abstract}

\section{Introduction}

Agriculture is one of the principal sectors of Ghana's economy. The country has for the past few years experienced continuous decline in GDP contribution from the sector, but it still remains the foundation on which the country's economy rests. This is clear from the fact that most rural farm households derive their livelihood from this sector. The sector contributed $22.0 \%$ against $28.6 \%$ from the industrial sector and $49.5 \%$ from the services sector to the GDP of the country [1]. In Ghana, the agricultural sector is principally dominated by small-scale farmers. Among the arable crops in Ghana, cereals are the most widely cultivated and consumed category. Maize continues to lead as the most important staple food in Ghana. This is because maize is very important for improving food security and poverty reduction as it is the staple food for most Ghanaians. In 2013, 1,764,477 MT of maize was produced and out of this value, Ashanti Region which was the third largest production region recorded a value of 201,786 MT [2]. Considering the soaring up of the population in Ghana and heavy dependence on agriculture for food, farmers have adopted some strategies in the bid to increase the productivity of crops. These are an intensive use of land, agrochemical usage, irrigation, disease and pest resistant varieties, and so forth. Farmers are highly motivated to using these strategies due to the emphasis placed by most agricultural development policies in Ghana which suggest the use of external inputs such as machinery and agrochemicals as the panacea to increasing food productivity. This has led to increasing the use of synthetic agrochemicals instead of the biological, cultural, and mechanical method for boosting production, controlling pest, weed, and disease [3]. 
Agrochemical is any chemical that is used in agricultural production to improve productivity and control of pest and diseases [4]. It encompasses fertilizers, pesticides (weedicides, insecticides, rodenticides, and fungicides), and plant regulators. In the bid to control maize pests such as stem borers, armyworms, silkworm, and weevils, weeds, and maize diseases such as downy mildew, maize rust, leaf blight, and leaf spot, for improvement in productivity, maize farmers have over the years resorted to the use of agrochemicals. The types of agrochemicals used are grouped into pesticides (fungicides, herbicides, insecticides, rodenticide, etc.) and fertilizers.

According to Horna et al. [5], the use of pesticides by farmers to control weeds, increase agricultural productivity, and preserve agricultural produce has reached a crescendo thereby calling for urgent attention. There are concerns about the indiscriminate use of agrochemicals with nonadherence of safety precautions of agrochemical use by maize farmers in Ghana (including Ejura-Sekyedumase Municipality). The use of Personal Protective Equipment (PPE) remains a thing of choice to these maize farmers. Other precautionary measures like avoiding of eating, drinking, and smoking during agrochemical application is still not adhered to by farmers. Instead of farmers properly disposing of empty containers of agrochemicals, they use them for fetching water, keep cooked food in them, store seed stocks for next season usage, and so forth.

Many farmers do not have adequate knowledge and information on the health hazards associated with handling and use of pesticides [6]. According to Okoffo et al. [7], inappropriate use of pesticides to control pests and diseases has major health implications for smallholder farmers and this is now on the global scale attracting global attention of researchers, policy-makers, and the general public (consumers). Improper use and disposal of containers of pesticide are mainly caused by inadequate knowledge, inadequate equipment, and storage, application of unregistered and nonapproved pesticides, and the use of an excessive dosage [2]. The exposure of farmers to agrochemicals has short term and long term effects $[8,9]$.

The ability to apply the right quantity is dependent on awareness of the health implications and the physiological effect on crop output and the quality of the produce. Agrochemicals affect maize crops directly. Overdose and much exposure of maize plant to agrochemicals cause scorches, yellowing, necrosis of the foliage, and distortions of the leaves. In this instance, a higher rate of application has the potency to affect maize output level. Residues of agrochemicals sometimes remain in maize edible parts which have a health impact on the consumer.

Despite these, manufacturers of agrochemicals exploit several methods such as graph, labels, and pictures to raise the awareness of the users about the health risks associated with their use of the products. Government agencies (Ministry of Food and Agriculture, Standard Board and Environmental Protection Agency) and Nongovernmental Organizations (NGOs) have not relented on their efforts to creating farmers' awareness of health implications of agrochemical use. Meanwhile, the achievable targets have not been reached. This means that there are certain socioeconomic and demographic factors that influence the farmer's awareness level of health implications of agrochemical use. The study, therefore, seeks to assess the factors that influence the farmers' awareness of health implications of agrochemical use as well as the effect of the awareness on maize output. The study is expected to contribute significantly to information and knowledge on the factors that influence maize farmers' awareness levels of health implications of agrochemical use. The study will also provide information to policy-makers and agricultural extension officers to come out with effective training programs for farmers. It is, therefore, important to know the limiting factors to farmers' awareness of health risks associated with agrochemical use. The research outcome can, therefore, be used by the Ministry of Agriculture, agrochemical companies, and other agencies to raise awareness of the need for safe handling and use of agrochemical by farmers through the identification of the drivers that influences farmers' level of awareness of health implications of agrochemical use.

Pesticides Use in Ghana. The use of agrochemicals, particularly pesticides, has become an integral part of the Ghanaian agricultural activities, being used on cash crops, cereals, fruits, and vegetable production. Dinham [10] reported that about $87 \%$ of vegetable farmers use chemical pesticides to control pests and diseases. In Ghana, the Environmental Protection Agency (EPA) is the regulatory body that oversees the use of recommended pesticides. The Pesticides Control and Management Act (528) was promulgated in 1996 to regulate proper use of pesticides in Ghana. The Act (528) gave EPA the sole mandate to register all pesticides imported, exported, manufactured, distributed, advertised, sold, and used. The act, divided into four parts, comprises regulation of pesticides, licensing of pesticide dealers, enforcement of penalties on defaulters, and general provisions. The full implementation of the provisions of the act is done by EPA with the help of Ghana Ports and Harbors' authority (GPHA), Customs Exercise and Preventive Service (CEP'S), Ghana Standards Board (GSB), Ministry of Food and Agriculture (MoFA), and Factory Inspectorate Department of Ministry of Employment and Social Welfare. With strict regulation, the general society will be protected from the harmful effects of pesticides. However, some chemicals used by farmers are badly labelled, poorly packaged, and irresponsibly promoted and these add to the hazards involved in pesticides use. Thus, the implementation of the act is not followed of late, hence the urgent need to review the safety precautions in pesticides use [11].

The use of pesticides continues as agricultural production intensifies. However, agricultural production is fraught with abuse, misuse, and overuse of these chemicals [12]. Associated with increased and inappropriate use and handling of agrochemicals are environmental and health problems. Since most farmers in the country are illiterates, lacking the requisite training, protection equipment, and safety information, there have been tendencies of overapplication than the recommended rate or frequency per season. Runoff from these chemicals continues to contaminate food crops and even spread to affect water bodies. The problem is 
TABLE 1: Extent of awareness of health implications of agrochemical use.

\begin{tabular}{lcc}
\hline The extent of awareness $(\lambda)$ & Ranges of indices & Ordered indicators of $\lambda$ \\
\hline Low level of awareness & $0 \leq \lambda \leq 0.49$ & 1 \\
Moderate level of awareness & $0.5 \leq \lambda \leq 0.69$ & 2 \\
High level of awareness & $0.7 \leq \lambda \leq 1$ & 3 \\
\hline
\end{tabular}

compounded by the fact that farmers usually wash knapsack sprayers and their clothes in water bodies after spraying. Meanwhile, most rural folks depend on lakes, streams, and rivers as sources of drinking water thereby linking chemical contamination exposures closely with toxicity. It has been demonstrated from previous studies that residues of both banned and currently used pesticides such as organochlorines and organophosphates, respectively, have been found in terrestrial food and aquatic environments [13-15]. Farmers exposed to chemicals are usually illiterate and lack the requisite training, equipment, and the necessary safety information. Farmers usually apply these hazardous agrochemicals like organochlorines and organophosphate more than the recommended rate or frequency per season. In Ghana, most rural folks depend on lakes, streams, and rivers as sources of drinking water. Meanwhile, these sources of water are not free from residues of pesticides as farmers usually wash knapsack sprayers and their clothes into these water sources after spraying. According to NPAS [16], chemical pesticides destabilize agroecological systems and biodiversity by contaminating the environment. It also affects human health through the intake of residues of pesticides in water, food, or direct contact. The effects of pesticides on human health are compounded since some farmers allow children to do the spraying without personal protective gears. Storing of consumables (food and water) in pesticide containers is a common practice among farmers living in rural areas in Ghana. Pesticides have contributed to several recent deaths and an untold number of illnesses in Upper East Region of Ghana [16].

\section{Methodology}

2.1. Theoretical Concept. According to Lichtenberg and Zilberman [17], the use of pesticides is considered protective inputs but not productive inputs. In general perspectives, agrochemical (pesticides and fertilizer) are used as both protective and productive inputs for maximum productivity. The safety use of recommended dosage of agrochemicals by a farmer is implicitly determined by the satisfaction or the utility that the farmer derives from adhering to the safety and dosage specifications. Therefore, the theoretical concept for analyzing the determinants of safety usage of agrochemical is the theory of utility maximization. Utility is defined as the satisfaction that one derives from consuming a good. This definition is valid when one is looking at the theory of consumer behavior. In this study, utility is defined as the satisfaction (equivalently measured as the benefit) a farmer derives from adhering to safety precautions and recommended dosage of agrochemicals. The conceptual reasoning is that farmers who have higher level of awareness about the health implications of agrochemical usage are likely to adhere to the recommended safety precautions. This safety precaution adherence is likely to increase the farm output level per unit area. A maize farmer would want to be more aware of health implications of agrochemical use if the utility he derives from being more aware is greater than the utility of being less aware. Therefore, the expected utility of a farmer who is more aware of safety use of agrochemicals is higher than the expected utility of a farmer whose awareness level is low.

$$
E\left(U_{i 1}\right)>E\left(U_{i 0}\right),
$$

where $U_{i 1}$ is the expected utility for farmers who are more aware of safety use of agrochemicals and $U_{i 0}$ is the expected utility for farmers who are less aware of safety use of agrochemicals.

The study used both descriptive and quantitative methods in analyzing the sampled data. Descriptive statistics such as percentages were used while ordered logit model was used to identify factors influencing farmers' awareness level of health implications of agrochemical use. To estimate the effect of awareness level on farm output, multiple linear regression model was used where awareness level is an additional explanatory variable measuring the effect on output.

In measuring the levels of awareness of health implications of agrochemical use (for simplicity, let us use the symbol $\lambda$ to indicate farmers' awareness level), a total of 15 awareness indicative questions (see Appendix) were posed to farmers. They were then scored 1 for awareness and 0 otherwise.

Farmers' score indicating the extent of awareness is specified in the equation [2]

$$
\begin{aligned}
& \lambda_{i} \\
& =\frac{\text { Total number of awareness scores recorded by } i \text { th farmer }}{15},
\end{aligned}
$$

where $\lambda_{i}$ denotes the level of awareness of health implications of agrochemical use by $i$ th farmer. The interpretations of indices of level of awareness of health implications of agrochemical use are indicated in Table 1.

2.1.1. The Ordered Logit Model. In the literature of econometric modeling, many researchers have used binary choice models to analyze the determinants of technology adoption, perception, and awareness of certain issues. Prominent among these binary choice models are linear probability model (LPM), binary probit, and binary logit models. The probit and logit models are improvement of the LPM but there are no significant differences between the results obtained from the two especially when the sample size is 
TABLE 2: Definitions and measurements of variables included in the models.

\begin{tabular}{|c|c|c|c|}
\hline Variables & Description & Measurements & Expected sign \\
\hline$L$ & Labor & Man-days & + \\
\hline FS & Farm size & Acres & + \\
\hline$P$ & Pesticides & Liters & $+/-$ \\
\hline$\lambda$ & Level of awareness of health implications of agrochemical use & $\begin{array}{c}1=\text { low level of awareness } \\
2=\text { moderate level of } \\
\text { awareness } \\
3=\text { high level of awareness }\end{array}$ & + \\
\hline $\mathrm{Ag}$ & Age of respondents & Years & - \\
\hline Ms & Marital status & $1=$ married, $0=$ otherwise & $+/-$ \\
\hline HHS & Household size & Number & + \\
\hline Edu & Years of schooling & Years & + \\
\hline Ext & Number of agric. extension officers' visits in years & Number & + \\
\hline Cre & Credit access & $1=$ access, $0=$ otherwise & + \\
\hline NCS & Number of children in school & Number & + \\
\hline Inc & Previous year's farm income & Ghana Cedis & + \\
\hline FBO & Membership of farmer-based-organization & $1=$ member, $0=$ otherwise & + \\
\hline OTVR & Ownership of television and radio & $1=$ yes, $0=$ otherwise & + \\
\hline
\end{tabular}

small [18]. As the name suggests, the distribution of the logit model is logistic function whereas the probit model has a normal probability distribution. In a situation where the dependent variable is polychotomous and ordered, dichotomous regression models such as LPM, binary probit, or binary logit models are inappropriate. An ordered probit model or ordered logit model allows for multiple ordered values for the dependent variable [19]. In order to use ordered logit model, the dependent variable $\lambda$ was ordered (see Table 2). In this study, the level of awareness of health implications of agrochemical use was ordered as shown in (3). Theoretically, the probability of farmers in the various levels of awareness of health implications of agrochemical use is indicated in (4). Also, the theoretical model for the log-odd is shown in (5).

$$
\begin{aligned}
& \lambda_{i}=1 \quad \text { if } 0<\lambda_{i}^{*} \leq 1, \\
& \lambda_{i}=2 \quad \text { if } 1<\lambda_{i}^{*} \leq 2, \\
& \lambda_{i}^{*}=3 \quad \text { if } 2<\lambda_{i}^{*} \leq 3, \\
& P(\lambda=0)=P\left(\lambda^{*}=0\right)=P\left(0=\beta X_{i}+\mu_{i}\right), \\
& P(\lambda \leq 1)=P\left(\lambda^{*} \leq 1\right)=P\left(1 \leq \beta X_{i}+\mu_{i}\right), \\
& P(\lambda \leq j)=P\left(\lambda^{*} \leq j\right)=P\left(j=\beta X_{i}+\mu_{i}\right), \\
& P\left(\lambda_{i} \leq \frac{j}{X_{i}}\right)=F\left(Z_{i}\right)=\frac{e^{Z_{i}}}{1+e^{Z_{i}}}=\frac{1}{1+e^{-Z_{i}}} .
\end{aligned}
$$

It is important to note that the terms of the indices are $1,2,3$ and hence, $u_{1}<u_{2}<u_{3}<u_{4}$.

2.1.2. Empirical Ordered Logit Model. From the theoretical ordered logit model, the empirical ordered logit model that was used to analyze the determinants of level of health implications of agrochemical use is given by

$$
\begin{aligned}
\ln \left(\frac{P_{j}}{1-P_{j}}\right)= & \beta_{o}+\beta_{1} \mathrm{FS}_{i}+\beta_{2} \operatorname{Sex}_{i}+\beta_{3} \mathrm{Edu}_{i} \\
& +\beta_{4} \operatorname{Exp}_{i}+\beta_{5} \mathrm{HHS}_{i}+\beta_{6} \mathrm{Ext}_{i} \\
& +\beta_{7} \mathrm{NCS}_{i}+\beta_{8} \mathrm{Inc}_{i}+\beta_{9} \mathrm{FBO}_{i} \\
& +\beta_{10} \mathrm{OTVR}_{i}+\mu_{i} .
\end{aligned}
$$

2.2. Effects of Awareness of Health Implications of Agrochemical Use on Maize Output. The multiple linear regression model was used to analyze how output is affected by level of awareness of health implications of agrochemical use. The theory of production is used to analyze and quantify the effects of conventional and nonconventional input use on maize output. Output is a function of conventional inputs such as labor, capital, fertilizer, and pesticides. Meanwhile, unconventional inputs such as level of awareness of health implications of agrochemical use can affect the quantity and quality of maize produced. Quantity of maize output is used in most studies to the neglect of quality of the produce. In this study, the maize output refers to the quantity and quality of maize output. Quality here refers to the quantity of maize devoid of chaff and other pests infected grains.

The empirical multiple regression model for analyzing the effect of level of health implications of agrochemical use on the maize output is given by

$$
\begin{aligned}
Y_{i}= & \alpha_{0}+\alpha_{1} L_{i}+\alpha_{2} \mathrm{FS}_{i}+\alpha_{3} P_{i}+\alpha_{4} \lambda_{i}+\alpha_{5} \mathrm{Ag}_{i}+\alpha_{6} \mathrm{MS}_{i} \\
& +\alpha_{7} \mathrm{HHS}_{i}+\alpha_{8} \mathrm{Edu}_{i}+\alpha_{9} \mathrm{Ext}_{i}+\alpha_{10} \mathrm{Cre}_{i}+\varepsilon_{i} .
\end{aligned}
$$


TABLE 3: Summary statistics of continuous variables.

\begin{tabular}{lcccc}
\hline Variables & Minimum & Maximum & Mean & Std. deviation \\
\hline Age & 20 & 76 & 40.5 & 4.156 \\
Years of education & 0 & 15 & 6 & 4.802 \\
Household size & 1 & 16 & 0.416 & 3.162 \\
Number of extension visits & 0 & 4 & 3 & 0.729 \\
Number of children in school & 0 & 8 & $4.24 E+02$ & 2 \\
Annual income (GH\&) & 480 & 13800 & 4.909 & 2822 \\
Farm size (acres) & 1 & 23 & 4.837 & 3.076 \\
Quantity pesticides (lit/acre) & 2 & 7 & 85.6 & 1.146 \\
Quantity of fertilizer (kg/acre) & 0 & 21 & 13.24 & 0.629 \\
Labor (man-days) & 8 & & 2.656 \\
\hline
\end{tabular}

Source: field survey (2015).

The explanatory variables included in the output model are defined with their expected directions of effects shown in Table 2.

2.3. Study Area, Sampling, and Data Collection Technique. The study was conducted in Ejura-Sekyedumase Municipality in the Ashanti Region of Ghana. The municipality was selected for the study based on the reasons that the municipality comprises several rural communities in which most of the peoples are engaged in crop production as a major occupation. Maize cultivation is dominant compared with other crops with high use of agrochemicals. EjuraSekyedumase Municipality was curved out of the former Sekyere and Offinso District in 1988 with the legislative instrument PNDC LI 1400, 1988 [20]. The municipality is located within longitudes $1^{\circ} 5^{\prime} \mathrm{W}$ and $1^{\circ} 39^{\prime} \mathrm{W}$ and latitudes $7^{\circ} 9^{\prime} \mathrm{N}$ and $7^{\circ} 36^{\circ} \mathrm{N}$. It is located in the northern part of the Ashanti Region.

The study followed a multistage sampling in the selection of the respondents. Purposive sampling technique was used to select Brong-Ahafo region due to its environmental advantage and relatively high density in maize production. The municipality was randomly selected among the many maize producing districts or municipality in the region. We randomly selected four communities from the list of maize producing communities within the municipality. To aid the process of sampling maize farm households from the communities within the municipality, a list of maize farmers was obtained from the extension department of the district Ministry of Food and Agriculture (MoFA) office. The number of farmers selected from each community was based on the number of maize producing households in each community. Simple random sampling technique was used to select 154 maize farmers from the four communities and used for the study. Enumerators were well trained to administer a well-structured questionnaire through faceto-face interviews. The face-to-face interviews were used due to its appropriateness in clarifying questions in the questionnaires.

\section{Results and Discussions}

3.1. Socioeconomic and Demographic Characteristics. Table 3 shows the summary statistics of some of the variables describing the socioeconomic characteristics of the respondents. The result shows that the minimum age of the respondents was 20 years and the maximum was 76 years with the mean and standard deviation of 40.5 years and 13.2 years, respectively. The attainment of formal education is very necessary for the use of agrochemicals. Education helps farmers to understand the regulations guiding the use of chemicals in the farms thereby exposing them to the dangers of inappropriate use of the chemicals. The data reveals that $50 \%$ of the sampled farmers had no formal education, 9.09\% had primary education, $28.57 \%$ had middle school or junior high education, and $12.34 \%$ had secondary or senior high education. Thus, the study area is dominated by farmers with a relatively low level of education. The minimum and maximum household sizes were 1 person and 16 persons, respectively, with a mean of 6 persons per household.

On the average, the number of extension visits was 0.416 times per year, which indicates poor extension services in the study area. Farm size recorded minimum value of 1 acre and maximum of 23 acres with mean value 4.909 acres. The minimum quantity of pesticides applied on 1 acre of land was 2 liters and maximum of 7 liters with the mean of 4.8 liters. Also, fertilizer applied on 1 acre recorded minimum value of $0 \mathrm{~kg}$ and maximum of $150 \mathrm{~kg}$ ( 3 bags) with a mean value $85.6 \mathrm{~kg}$.

3.2. Farmers' Practices of Usage of Agrochemicals. The empirical results from the study indicate that most of the farmers (66.2\%) do not read the labels on the containers/packages of agrochemicals, while 33.8\% read the labels before use (see Table 4). About $25 \%$ of those who cannot read seek help from others who can read. It was also revealed that $31 \%$ of the farmers understand the labels after reading. About $68 \%$ of the farmers stated that they do not eat, drink, or smoke during chemical application and 32.5\% admitted that they do. From 
TABLE 4: Farmers response to indicators of awareness of health implications of agrochemical use.

\begin{tabular}{|c|c|c|}
\hline Indicators of awareness of health implications of agrochemical use & Response & Percentage (\%) \\
\hline \multirow{2}{*}{ Reading of labels on the package/container } & Yes & 33.8 \\
\hline & No & 66.2 \\
\hline \multirow{2}{*}{ Seeking help from others, if cannot read } & Yes & 25.3 \\
\hline & No & 74.7 \\
\hline \multirow{2}{*}{ Awareness of agrochemical toxicity } & Yes & 86.4 \\
\hline & No & 13.6 \\
\hline \multirow{2}{*}{ Understanding of the level of toxicity, reading the labels on the label } & Yes & 31 \\
\hline & No & 69 \\
\hline \multirow{2}{*}{ Eating, drinking, or smoking while spraying or applying agrochemicals } & Yes & 32.5 \\
\hline & No & 67.5 \\
\hline \multirow{2}{*}{ Washing of hands with soap right after spraying or applying agrochemicals } & Yes & 83.1 \\
\hline & No & 16.9 \\
\hline \multirow{2}{*}{ Keeping of bottles/packages of agrochemicals along with food items } & Yes & 46.8 \\
\hline & No & 53.2 \\
\hline \multirow{2}{*}{ Washing of the sprayer in the pond/canal/river } & Yes & 13 \\
\hline & No & 87 \\
\hline \multirow{2}{*}{ Determination of wind direction } & Yes & 77.3 \\
\hline & No & 22.7 \\
\hline \multirow{2}{*}{ Facing of the wind direction when spraying } & Yes & 74 \\
\hline & No & 26 \\
\hline \multirow{2}{*}{ Application of recommended dosage } & Yes & 52.6 \\
\hline & No & 47.4 \\
\hline \multirow{2}{*}{ Application of two or more pesticides type together } & Yes & 68.3 \\
\hline & No & 31.7 \\
\hline \multirow{2}{*}{ Can overdose of agrochemicals affect maize stand? } & Yes & 62.1 \\
\hline & No & 37.9 \\
\hline \multirow{2}{*}{ Use of agrochemicals to store foodstuffs for consumption or animals feeding } & Yes & 34.2 \\
\hline & No & 65.8 \\
\hline \multirow{2}{*}{ Use of personal protective gears during agrochemical spraying or application } & Yes & 26 \\
\hline & No & 74 \\
\hline
\end{tabular}

Source: field survey (2015).

the results, about $83 \%$ of said they wash their hands with soap after agrochemical application.

In the area of reuse of empty containers of agrochemicals, $53.2 \%$ said they dispose of them while $46.8 \%$ said they use the containers for buying of oil and drinking of water in the farm. Out of 154 respondents, $13 \%$ of the responded indicated that they wash the spraying machine in water bodies like rivers and streams. From the results, $77.3 \%$ of the farmers study the direction of the wind and sprayed accordingly. Additionally, $52.6 \%$ of the respondents adhere to the recommended dosage while $47.4 \%$ do not. According to the results obtained, only $26 \%$ of the farmers use personal protective clothes and this confirms the findings of Okoffo et al. [7] that less than half of cocoa farmers (35\%) in Brong-Ahafo region of Ghana put on full PPE (costume) during pesticide application. Mattah et al. [21] in their research on "pesticide application among farmers in the catchment of Ashaiman Irrigation Scheme of Ghana: health implications" revealed that out of 74 farmers observed spraying pesticides on their farms, $36.5 \%$ used nose guards, $45.9 \%$ used boots, $31 \%$ used hand gloves, and $25.7 \%$ wore dresses that covered the whole body except the eyes.

3.3. Level of Awareness of Health Implications of Agrochemical Use. There is a direct correlation between farmers' agrochemicals use practices, the attitude of farmers, and their awareness level of its health effect on them and the environment at large. Farmers' awareness levels were calculated from their responses on agrochemical application practices and health awareness indicators. The awareness levels were ordered on a scale of 1 ( $0-49 \%$ score), 2 (50-69\% score), and 3 (above $70 \%$ score) indicating a low, medium, and high level of awareness which is also a measure of the intensity of awareness. The results indicated that $35.6 \%$ had a low level of awareness, $51.4 \%$ were moderately aware, and only $13 \%$ of the respondents had a high level of awareness (Figure 1). The average awareness score of farmers interviewed was $58 \%$ indicating that maize farmers in the study area are moderately aware of agrochemical usage and its health implications. 
TABLE 5: Marginal effects of ordered logit model and the individual awareness levels.

\begin{tabular}{|c|c|c|c|c|c|c|c|c|}
\hline \multirow{2}{*}{ Variables } & \multicolumn{2}{|c|}{ Ordered logit model } & \multicolumn{2}{|c|}{ Low level } & \multicolumn{2}{|c|}{ Moderate level } & \multicolumn{2}{|c|}{ High level } \\
\hline & Marginal effects & $p$ value & Marginal effects & $p$ value & Marginal effects & $p$ value & Marginal effects & $p$ value \\
\hline Fs & $-0.327^{* *}$ & 0.010 & $0.068^{\mathrm{a}}$ & 0.012 & -0.051 & 0.022 & -0.017 & 0.023 \\
\hline Sex & 0.663 & 0.180 & -0.149 & 0.203 & 0.119 & 0.232 & 0.029 & 0.132 \\
\hline Edu & $0.113^{* *}$ & 0.002 & $0.028^{\mathrm{a}}$ & 0.002 & 0.021 & 0.007 & 0.007 & 0.001 \\
\hline Exp & $-0.064^{*}$ & 0.032 & $0.013^{\mathrm{a}}$ & 0.032 & -0.001 & 0.045 & -0.003 & 0.048 \\
\hline $\mathrm{HHs}$ & -0.074 & 0.348 & 0.015 & 0.349 & -0.015 & 0.354 & -0.004 & 0.358 \\
\hline Ext & 0.116 & 0.678 & 0.024 & 0.677 & 0.018 & 0.678 & 0.006 & 0.679 \\
\hline NCS & $0.341^{* *}$ & 0.004 & $-0.071^{\mathrm{a}}$ & 0.004 & 0.053 & 0.001 & 0.018 & 0.014 \\
\hline Inc & 0.000 & 0.024 & -0.001 & 0.027 & 0.001 & 0.04 & 0.001 & 0.001 \\
\hline FBO & 0.043 & 0.912 & -0.009 & 0.912 & 0.007 & 0.912 & 0.002 & 0.913 \\
\hline OTVR & $1.422^{* *}$ & 0.000 & $-0.312^{\mathrm{a}}$ & 0.001 & 0.245 & 0.002 & 0.066 & 0.004 \\
\hline
\end{tabular}

Number of observations $=154$; $\log$-likelihood $=-112.3836$; pseudo $R^{2}=0.246$;

$\mathrm{LR} \mathrm{chi}^{2}=73.51$; prob $>\mathrm{chi}^{2}=0.00 ;{ }^{* *}$ significant at $1 \% ;{ }^{*}$ significant at $5 \% ;{ }^{\mathrm{a}}$ representing significant variables in all the three levels of awareness.

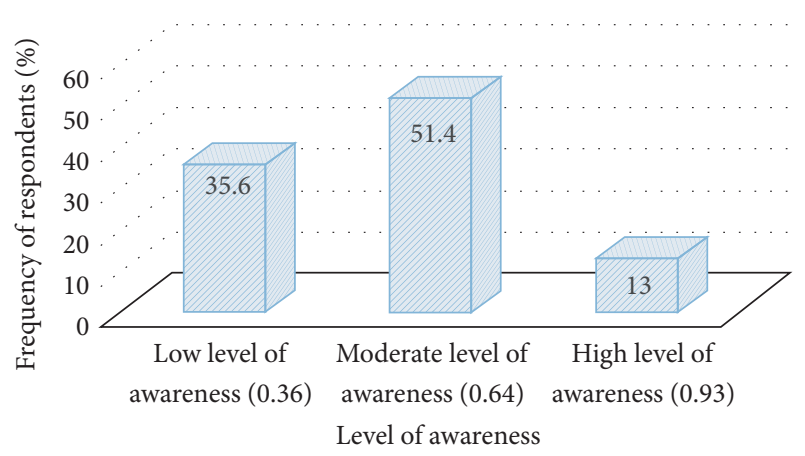

FIGURE 1: Level of awareness and frequency of respondents. Source: author's computations from field survey, 2015.

The study confirmed the findings of Fianko et al. [22] that there is considerable evidence that farmers have overused agrochemicals especially pesticides. It is also consistent with Omari [4] findings that farmers have a low level of awareness of the hazards associated with the use of agrochemicals. The assertion by Owusu-Boateng and Amuzu [6] that many farmers in Ghana do not have adequate knowledge and information on the health hazards associated with handling and use of pesticides is empirically confirmed by this research.

\subsection{Determinants of Level of Awareness of Health Implications.} An ordered logit model was used to identify the factors that affect maize farmers' level of awareness of health implications of agrochemicals $(\lambda)$. Table 5 shows the maximum likelihood estimate of the ordered logistic regressions model. The $p$ value for the Chi-squared test of 0.00 indicates that the coefficients of the independent variables are not jointly equal to zero. Chi-squared tests of the equality of the two cutoff points are rejected at $p$ values of 0.00 or less. The significant differences in the cutoff points indicate that the three categories statistically and significantly differ and hence all the three categories should be included in the model. The explanatory variables explain $21 \%$ (pseudo $R^{2}$ ) variations in the awareness level.

The socioeconomic factors that were included in the model are sex, household size, education, farmer group membership, the number of children in school, ownership of $\mathrm{TV} /$ radio, experience in maize farming, income, farm size, and extension visits. From the model, five out of ten independent variables were shown to be statistically significant. The results showed that education, the number of children in school, and ownership of TV/radio positively influence farmers' level of awareness of health implications of agrochemicals use. Experience in agrochemicals use and farm size have a negative significant effect on farmers' level of awareness of health implications of agrochemicals use. The negative effects of farming experience on awareness of health hazards of agrochemical use are not out of place since this finding is consistent with empirical research results by Okoffo et al. [7]. Extension visit was not statistically significant and this could be that agricultural extension agents do not advise farmers on safety use of agrochemicals. Juxtaposing these findings on the summary statistics of continuous variables shown in Table 4, it is clear that an average number of annual extension visits of 0.416 are too low to actually provide enough information on awareness of health implications of agrochemicals use.

The insignificant influence of income and FBO membership on farmers' awareness of health implications of agrochemical use is supported by the work of [7]. The estimated coefficients from an ordered logit model are difficult to interpret because they are in units of log-odds and for easy interpretation, marginal effects associated with each category were generated as shown in Table 6 . The margins are interpreted in relation to their signs and categories.

Farm size was shown to be significant at $1 \%$. It has a negative relationship with farmers' level of awareness of health implications of agrochemical use. This variable contradicted the a priori expectation. This implies that smallholder maize farmers are more aware of agrochemicals use risk than large-scale farmers holding other factors constant. This 
TABLE 6: Multiple linear regression results: level of awareness as driver of maize output.

\begin{tabular}{lcc}
\hline Variables & Coefficients (marginal effects) & Standard error \\
\hline Labor & 0.209 & 0.42 \\
Farm size & $5.840^{* * *}$ & 0.35 \\
Quantity of pesticides & $2.211^{* * *}$ & 2.11 \\
Level of awareness & $3.096^{*}$ & 1.98 \\
Age & -0.093 & 0.10 \\
Marital status & $2.318^{*}$ & 1.34 \\
Household size & $0.895^{* *}$ & 0.39 \\
Education years & $4.334^{*}$ & 0.78 \\
Extension visits & $4.344^{* * *}$ & 1.54 \\
Credit & 1.036 & 2.71 \\
\hline
\end{tabular}

Adj $R$-squared $=0.75 ;$ pro $>F=0.000 ; F(9,144)=42.38 ;{ }^{* * *}$ significant at $1 \%,{ }^{* *}$ significant at $5 \%$, and ${ }^{*}$ significant at $10 \%$.

could be that large-scale farmers do not apply pesticides by themselves regularly and usually get this job done by hired labor. It could also be as a result of resource constraint which hinders the provision of right quantities of agrochemicals and the accompanied protective gears. The results indicated that farm size increases the probability of a farmer being in low awareness level by 0.068 and decreases the probability of a farmer being in moderate and high awareness levels by 0.051 and 0.017 , respectively.

Years of education are significant at $1 \%$ which agrees with the a priori expectation suggesting a positive effect on the farmers' level of awareness of health implications of agrochemicals use. Educational attainment decreases the probability of a farmer being in the low level of awareness by 0.028 and increases the probability of being in moderate and high level of awareness by 0.021 and 0.007 , respectively. The reason could be that farmers who are educated can read and understand labels on agrochemical containers and adhere to safety standards. It is a confirmation of a research conducted by Gaber and Abdel-Latif [23] which opined that farmers who received school education had more knowledge about the negative effects of pesticides on health. The number of children in school was used as a proxy of information availability on safety use of agrochemicals to the farmer. This variable was significant at $1 \%$ and positively related to the level of awareness. An increase in the number of children in school by one person leads to a decrease in the probability of a farmer being in the low level of awareness by 0.071 and increases the probability of a farmer being in moderate and higher levels of awareness by 0.053 and 0.018 , respectively. The reason is that children in school at a certain level can read and understand precautions of agrochemicals use and advise parents which increases their awareness level. Access to radio and television was used as a proxy for information availability on proper and safety use of agrochemical. The results proved to be positively significant at $1 \%$. The result implies that farmers who have access to television and radio are more aware than those without radio, ceteris paribus. Access to television and radio decreases the probability of a farmer being in the low level of awareness by 0.312 and increases the probability of a farmer being in moderate and high levels of awareness by 0.245 and 0.066 , respectively.
This is because farmers who own radio and television receive information on safety use of agrochemicals. Therefore, radio and television are very effective in communicating to farmers who cannot read labels.

3.5. Effects of Level of Awareness of Health Implications of Agrochemical Use on Maize Output. A multiple linear regression model was used to analyze how output is affected by the level of awareness of agrochemical use risk. The Adjusted $R$-squared of 0.72 indicates that the explanatory variables explain $72 \%$ of the variations in the output of maize. The $p$ value of $F$-test is 0.00 implying that the model is statistically significant at $1 \%$ and hence the coefficients of the independent variables are not jointly equal to zero. The socioeconomic variables included in the Cobb-Douglas production function are labor, farmers' awareness levels of health implications of agrochemicals use, age, marital status, household size, years of education, extension contacts, credit, farm size, and quantity of pesticides. Table 6 shows the results of the multiple linear regression model. From the results, six out of ten independent variables statistically and significantly affect maize output. However, labor was found not significantly influencing maize output. On the contrary, Ajah and Nmadu [24] found labor to be positively influencing maize output. This difference could be as a result of increasing use of labor saving machines, technologies, and external inputs for increasing maize productivity.

Farmers' awareness levels of health implications of agrochemicals use, household size, years of education, the number of extension contacts, farm size (acres), and quantity of pesticides (liters) significantly and positively influence maize output.

It is important to know whether farmers who are aware of health implications of agrochemical use and adhere to the safety standards are able to obtain higher or lower maize output. This explanatory variable is found to be significant at $10 \%$. It has a positive effect on output and hence meets the a priori expectation. Awareness of health implications of agrochemical use increases output by $309 \mathrm{~kg}$ (3.09 bags) per acre. This means that if a farmer moves from low to moderate levels of awareness of health implications of agrochemical use, his or her maize output will increase by $309 \mathrm{~kg}$ (3.09 bags) 
per acre. Likewise, if a farmer moves from moderate to high levels of awareness of health implications of agrochemical use, his or her maize output will increase by $309 \mathrm{~kg}$ (3.09 bags) per acre. Farmers who are aware of health implications of agrochemical use will adhere to the recommended practices and application rate and this has a great implication for the crops yield and health of the farmers. This will lead to the avoidance of over/underapplication of agrochemicals and reduce the loss of time due to an illness of the farmer thereby increasing the efficiency and productivity of the crops and farmers. According to Glover-Amengor and Tetteh [25], apart from agrochemicals affecting the environment as poisons, most pesticides used in agriculture in Ghana also affect the crops directly by causing increases in yield at optimum rates and decreases in yield with increasing concentrations.

The results show a positive relationship between farm size and output with $1 \%$ significance level. The increase in area under cultivation by one acre leads to an increase in maize output by $584 \mathrm{~kg}$ ( 5.84 bags) ceteris paribus. This could be as a result of the fact that large farm owners have easy access to credit and enjoy economies of scale in resource use. This result is consistent with Awunyo-Vitor et al. [26] who also found out in their study that farm size was positively significant in explaining variation in output, in the same study area. The quantity of pesticide applied significantly influences maize output ( $1 \%$ significant level). The result shows that an increase in the quantity of pesticides by one liter leads to an increase in maize output by $221 \mathrm{~kg}$ ( 2.21 bags) holding other factors constant. Meanwhile, overuse can also cause loss. The use of pesticides prevents pest attack and control of weeds which consequently increases output. The result is consistent with Awunyo-Vitor et al. [26] findings in cowpea production. Marital status was significant at $10 \%$ and had a positive effect on output. Marriage increases maize output by $231 \mathrm{~kg}(2.31$ bags). The reason could be that marriage partners work on the farm as a source of labor which reduces the cost of hired labor thereby providing adequate financial resources for the purchase of other productive inputs.

Household size was significant at $5 \%$ and positively related to output. The positive relationship was in line with the a priori expectation. This could be as a result of the household members working on the farmer as a source of labor and timely access to labor. The increase of household size by one person leads to increase in output by $90 \mathrm{~kg}$ (0.9 bags) of maize. The finding is consistent with Ajah and Nmadu [24], who found that an increase in household size leads to an increase in maize output. Conversely, Achem et al. [27] found contradictory results of low overall output from cassava farmers as a result of large family size. Education years were hypothesized to be positively related to maize output. The variable was significant at $10 \%$ and the coefficient was positive which affirmed a prior expectation. The result shows that an increase in formal education by one year leads to an increase in maize output by $433 \mathrm{~kg}$ ( 4.33 bags). This is due to the fact that an educated farmer can manage farm resources better and has an advantage over uneducated farmer in understanding and adopting the recommended application rate of external inputs. Extension visit exposes farmers to improve production technologies and proper utilization of farm inputs. In this study, the number of extension visits had a positive relationship with maize output. It is statistically significant at $1 \%$ and confirms the a priori expectation. This implies that when the number of extension visits increases by one unit, maize output will increase by $434 \mathrm{~kg}$ ( 4.34 bags) holding other factors constant. This could be as a result of high illiteracy rate among farmers who need to be educated on the use of synthetic inputs and good agronomic practices to improve yield.

\section{Conclusions and Recommendations}

4.1. Conclusions. The study sought to identify factors that influence maize farmers' awareness of health implications of agrochemicals use and its impact on maize output in EjuraSekyedumase Municipality. Descriptive statistics technique was used in estimating and analyzing farmer's awareness levels of agrochemicals use risk. Ordered logit regression model was used to identify factors that affect farmers' level of awareness of health implications of agrochemical use. Augmented Cobb-Douglas production function was also used to quantify how awareness of health implications of agrochemical use affects maize output. $35.6 \%, 51.4 \%$, and $13 \%$ of the respondents had low, moderate, and high levels of awareness, respectively, of health implications of agrochemical use. The mean score of awareness of health implications of agrochemical use in the study area was 58\% indicating a moderate level of awareness. The main source of information on agrochemicals use was media and manuals. Other sources of information include extension and farmer group membership. It was revealed from the ordered logit regression that five out of ten explanatory variables, years of education, the number of children in school, ownership of $\mathrm{TV} /$ radio, experience in agrochemicals application, and farm size, were significant variables that influence farmers' levels of awareness of health implications of agrochemicals use in the study area. Awareness of health implications of agrochemical use significantly increases maize output. Other variables that were significant in output model include household size, years of education, the number of extension contacts, farm size, marital status, and quantity of pesticides applied.

4.2. Policy Recommendations. Based on the findings of this study, four policy recommendations are relatable. The study recognizes that education is important for improving farmers' awareness regarding health implications of agrochemicals use. It is therefore recommended that field training and practical educational programs on good and safety use of agrochemicals should be adopted by agencies to raise farmer's awareness level of the risk associated with agrochemical use. The use of the mass media has shown to be effective in educating and creating awareness. Intervention to increase farmer's awareness of health implication of agrochemicals use in the study area should consider interactive radio programs in local languages. Also, health implications of agrochemical use should be incorporated into our education curriculum. Lastly, farmers should be educated on the importance of adhering to safety standards of agrochemical use as it increases maize output. 
TABLE 7: Indicative questions for measuring awareness of health implications of agrochemical use.

\begin{tabular}{|c|c|}
\hline Indicators of awareness of health implications of agrochemical use & Awareness $(0=$ if not aware, $1=$ if aware $)$ \\
\hline Do you read the labels on the package? & Yes $=$ aware, no $=$ not aware \\
\hline If you cannot read, do you seek help from others? & Yes $=$ aware, no $=$ not aware \\
\hline Do you follow the instructions given on the label? & Yes $=$ aware, no $=$ not aware \\
\hline Are you aware of agrochemical toxicity? & Yes $=$ aware, no $=$ not aware \\
\hline Are you able to understand the level of toxicity, reading the sign on the label? & Yes $=$ aware, no $=$ not aware \\
\hline Do you eat, drink, or smoke while spraying or applying agrochemicals? & Yes $=$ not aware, no $=$ aware \\
\hline Do you wash your hands with soap right after spraying or applying agrochemicals? & Yes $=$ aware, no $=$ not aware \\
\hline Do you keep bottles/packages of agrochemicals along with food items? & Yes $=$ not aware, no $=$ aware \\
\hline Do you apply two or more pesticides' type together? & Yes $=$ not aware, no $=$ aware \\
\hline Do you wash the sprayer/bottle in pond/canal/river/others? & Yes $=$ not aware, no $=$ aware \\
\hline Do you spray when it is windy? & Yes $=$ not aware, no $=$ aware \\
\hline Do you determine the wind direction first before spraying? & Yes $=$ aware, no $=$ not aware \\
\hline Do you apply the recommended dosage? & Yes $=$ aware, no $=$ not aware \\
\hline Does overdose affect maize stand? & Yes $=$ aware, no $=$ not aware \\
\hline $\begin{array}{l}\text { Do you use personal protective gears such as gloves and overall clothing during agrochemical } \\
\text { spraying or application? }\end{array}$ & Yes $=$ aware, no $=$ not aware \\
\hline
\end{tabular}

Total number of aware scores

\section{Appendix}

See Table 7.

\section{Competing Interests}

The authors declare that they have no competing interests.

\section{References}

[1] Ghana Statistical Service (GSS), 2010 Population \& Housing Census National, Analytical Report, GSS, Accra, Ghana, 2013.

[2] Ministry of Food and Agriculture, Agriculture in Ghana, Statistics, Research and Information Directorate (SRID), Ministry of Food and Agriculture, Accra, 2014.

[3] A. V. F. Ngowi, "A study of farmers' knowledge, attitude and experience in the use of pesticides in coffee farming," African Newsletter on Occupational Health and Safety, vol. 13, pp. 6264, 2003.

[4] S. Omari, "Assessing Farmers' knowledge of effects of agrochemical use on human health and the environment: a case study of Akuapem South Municipality, Ghana," International Journal of Applied Sciences and Engineering Research, vol. 3, no. 2, 2014.

[5] D. Horna, M. Smale, M. Al-Hassan, R. J. Falck-Zepeda, and S. E. Timpo, "Insecticides use on vegetables in ghana: would GM seed benefit farmers?” IFPRI Discussion Paper 007855, 2008.

[6] G. Owusu-Boateng and K. K. Amuzu, "A survey of some critical issues in vegetable crops farming along river oyansia in opeibea and dzorwulu, Accra-Ghana," Global Advanced Research Journal of Physical and Applied Sciences, vol. 2, no. 2, pp. 24-31, 2013.

[7] E. D. Okoffo, M. Mensah, and B. Y. Fosu-Mensah, "Pesticides exposure and the use of personal protective equipment by cocoa farmers in Ghana," Environmental Systems Research, vol. 5, article no. 17, 2016.
[8] H. K. Gill and H. Garg, "Pesticides: environmental impacts and management strategies," in Pesticides-Toxic Aspects, S. Soloneski, Ed., pp. 188-230, InTech, Rijeka, Croatia, 2014.

[9] P. Cocco, G. Satta, S. Dubois et al., "Lymphoma risk and occupational exposure to pesticides: results of the epilymph study," Occupational and Environmental Medicine, vol. 70, no. 2, pp. 91-98, 2013.

[10] B. Dinham, "Growing vegetables in developing countries for local urban populations and export markets: problems confronting small-scale producers," Pest Management Science, vol. 59, no. 5, pp. 575-582, 2003.

[11] B. T. Tawiah, Concentration of organochlorine insecticide residues in tomato (Lycopersicon Esculentum) fruit: a case study at akumadan in the offinso North district of Ashanti region [Ph.D. thesis], Department of Theoretical and Applied Biology, Kwame Nkrumah University of Science and Technology, Kumasi, Ghana, 2013.

[12] K. A. Asante and J. W. Ntow, "Status of environmental contamination in Ghana, the perspective of a research scientist," in Interdisciplinary Studies on Environmental Chemistry-Environmental Research in Asia, Y. Obayashi, T. Isobe, A. Subramanian, S. Suzuki, and S. Tanabe, Eds., pp. 253-260, 2009.

[13] H. Kuranchie-Mensah, P. O. Yeboah, E. Nyarko, and A. A. Golow, "Studies on organochlorine pesticide residue in fishes from the Densu River Basin, Ghana," Bulletin of Environmental Contamination and Toxicology, vol. 90, no. 4, pp. 421-426, 2013.

[14] H. Kuranchie-Mensah, S. M. Atiemo, L. M. N.-D. Palm, S. Blankson-Arthur, A. O. Tutu, and P. Fosu, "Determination of organochlorine pesticide residue in sediment and water from the Densu river basin, Ghana," Chemosphere, vol. 86, no. 3, pp. 286-292, 2012.

[15] C. K. Bempah and A. K. Donkor, "Pesticide residues in fruits at the market level in Accra Metropolis, Ghana, a preliminary study," Environmental Monitoring and Assessment, vol. 175, no. 1-4, pp. 551-561, 2011. 
[16] Northern Presbyterian Agricultural Services (NPAS), Ghana's Pesticide Crisis: The Need for Further Government Action, Northern Presbyterian Agricultural Services (NPAS), Tamale, Ghana, 2012.

[17] E. Lichtenberg and D. Zilberman, "The econometrics of damage control: why specification matters," American Journal of Agricultural Economics, vol. 68, no. 2, pp. 262-273, 1986.

[18] M. Parhi, Diffusion of New Technology in Indian Auto Component Industry: An Examination of the Determinants of Adoption, Discussion Paper Series No. 8, United Nations University, Maastricht, The Netherlands, 2005.

[19] W. H. Greene, Econometric Analysis, Prentice Hall, New Jersey, NJ, USA, 7th edition, 2008.

[20] Ejura-Sekyedumase District Assembly, District Information, http://ejurasekyedumase.ghanadistricts.gov.gh/.

[21] M. M. Mattah, P. A. D. Mattah, and G. Futagbi, "Pesticide application among farmers in the catchment of ashaiman irrigation scheme of Ghana: health implications," Journal of Environmental and Public Health, vol. 2015, Article ID 547272, 7 pages, 2015.

[22] J. R. Fianko, A. Donkor, S. T. Lowor, and P. O. Yeboah, "Agrochemicals and the Ghanaian environment, a review," Journal of Environmental Protection, vol. 2, no. 3, pp. 221-230, 2011.

[23] S. Gaber and S. Abdel-Latif, "Effect of education and health locus of control on safe use of pesticides: a cross sectional random study," Journal of Occupational Medicine and Toxicology, vol. 7, article no. 3, 2012.

[24] J. Ajah and J. N. Nmadu, "Socio-economic factors influencing the output of small-scale maize farmers in Abuja, Nigeria," Journal of Social Science, vol. 33, no. 2, pp. 333-341, 2012.

[25] M. Glover-Amengor and F. M. Tetteh, "Effect of pesticide application rate on yield of vegetables and soil microbial communities," West African Journal of Applied Ecology, vol. 12, no. $1,2009$.

[26] D. Awunyo-Vitor, J. Bakan, and S. Coffie, "Estimation of farm level technical efficiency of small-scale Cowpea production in Ghana," American-Eurasian Journal of Agriculture and Environmental Science, vol. 13, no. 8, pp. 1080-1087, 2013.

[27] B. A. Achem, B. T. Mohammed, and J. J. Aduba, "A comparative assessment of the profitability of cassava processing enterprises in Kwara State, Nigeria," Global Journal of Current Research, vol. 1, no. 2, pp. 57-61, 2013. 


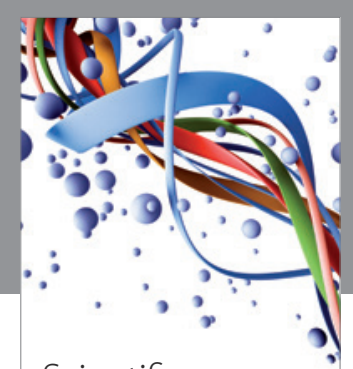

Scientifica
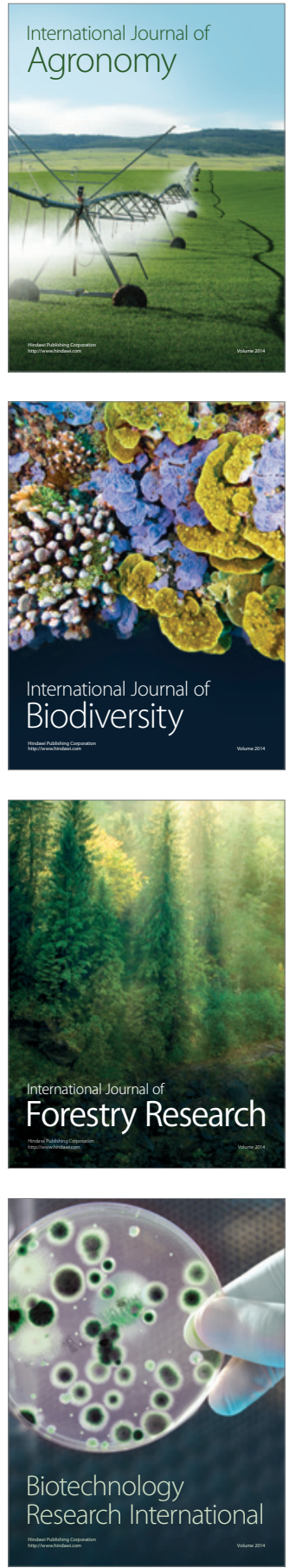
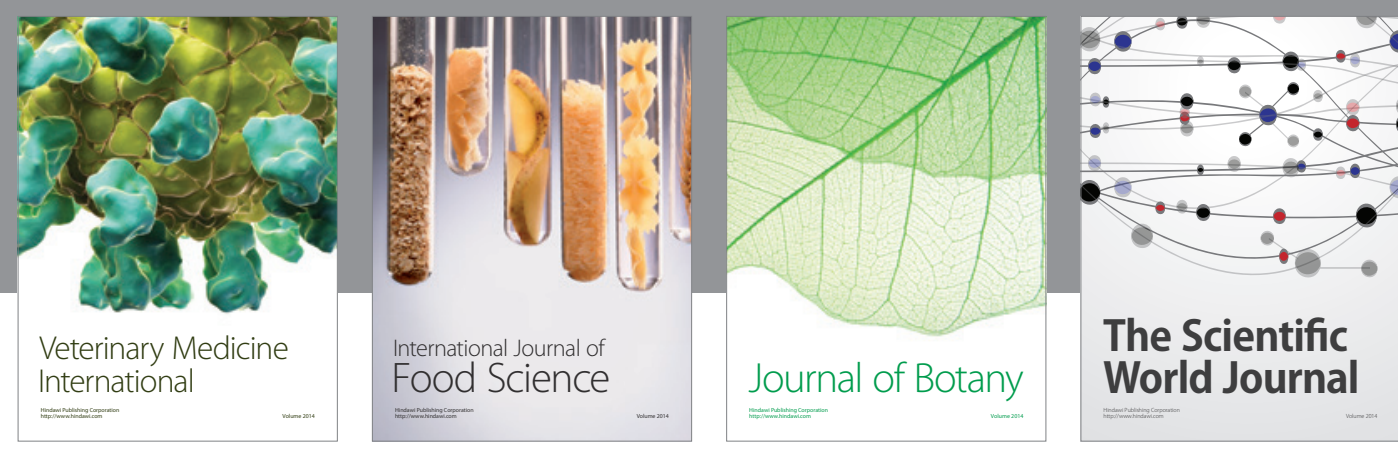

The Scientific

\section{World Journal}

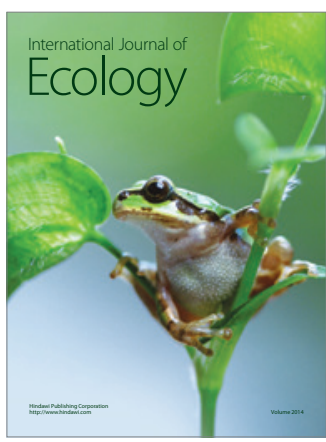

\section{Hindawi}

Submit your manuscripts at

https://www.hindawi.com
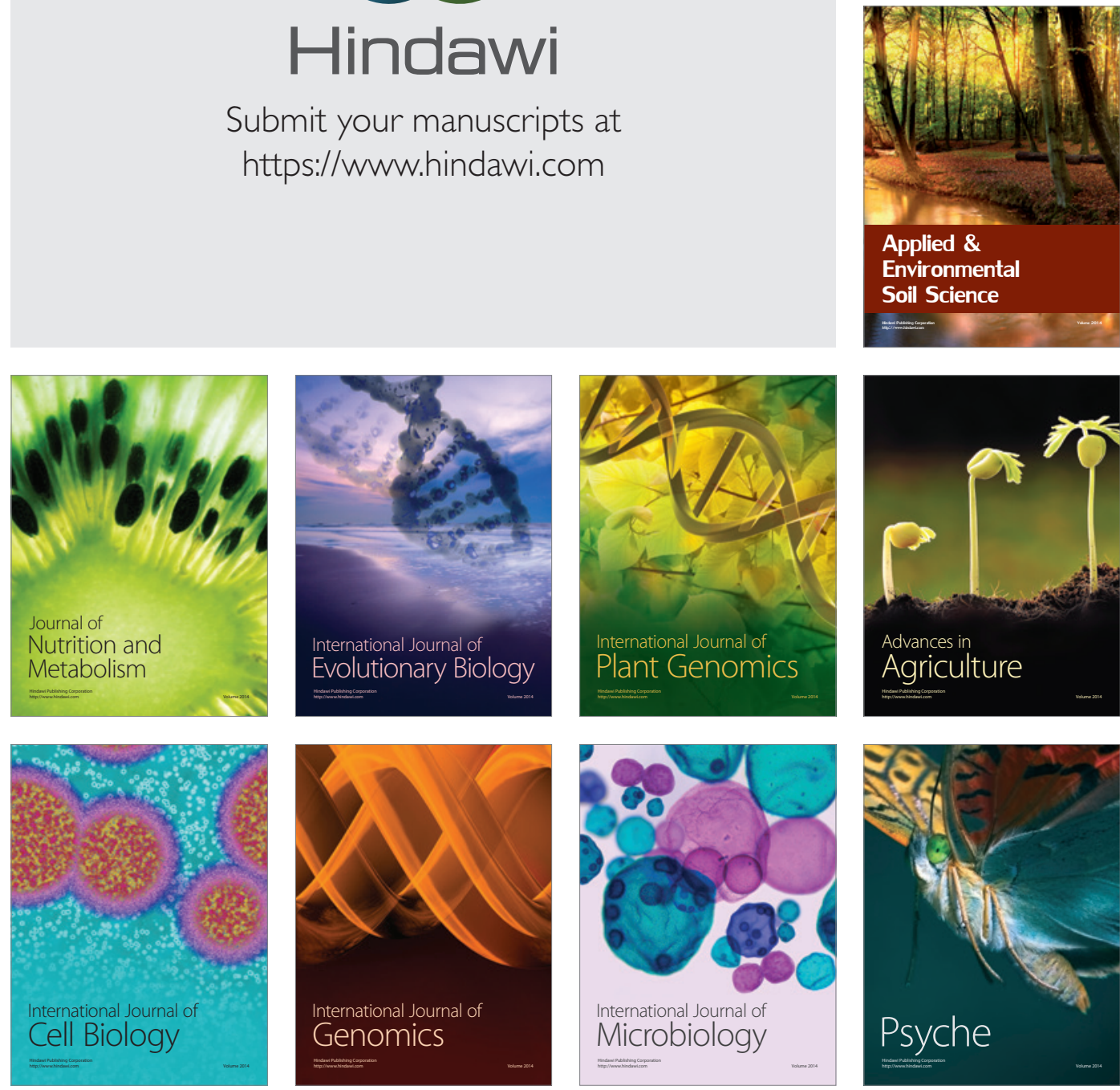
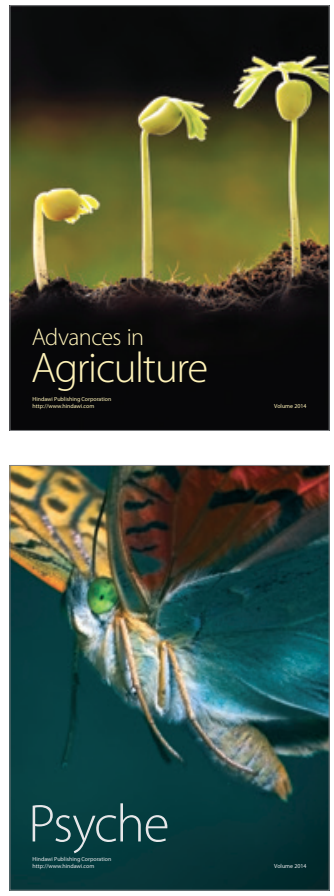